\title{
SEASONAL HABITAT USE PATTERN OF BLACKBUCK (ANTELOPE CERVICAPRA) AT KHAIRAPUR, BARDIA, NEPAL
}

\author{
S. Ban and N.B. Singh
}

\section{ABSTRACT}

The seasonal habitat use pattern of Blackbuck in Blackbuck Conservation Area (BCA) was studied by the division of the realized habitat of Blackbuck (1.74 sq. km) into three blocks $A, B$ and $C$. Direct count method and indirect count methods were used for the study of seasonal habitat use pattern of the animal. It was observed that block $A$ was mostly used by the animal followed by block $C$ and block $B$ respectively. The study focuses in the implementation of controlled and rotational livestock grazing in BCA as an effective wildlife management tool.

Keywords: controlled and rotational livestock grazing, realized habitat and wildlife management tool.

\section{INTRODUCTION}

Blackbuck (Antelope cervicapra), locally known as 'Krishnasaar' belongs to the subfamily 'Antilopinae' and order 'Artiodactyla'. The scientific name Antelope is restricted to Blackbuck only.

The Blackbuck is vulnerable as per the IUCN categories and is listed in the Appendix III of the CITES in Nepal (Chapagain and Dhakal 2002). The National Park and Wildlife Conservation Act 1973, has listed 27 species of protected mammals and Blackbuck is one of them.

It is typically South Indian in distribution but is also found in Nepal, Texas and Argentina. It was extinct from Bangladesh and Pakistan. In Nepal, before the malaria eradication programmes, reports by Dinerstein (1975) and Wegge and Wilson (1976) revealed the existence of two small remnant populations in the Bardia and Banke districts, respectively, of the Western Terai (Lehmkuhl 1979).

\section{STUDY AREA}

The study was done in BCA located at Khairapur and ward number 2, 3, 4 and 5 of Gulariya Municipality (20 $77^{\prime} 54^{\prime \prime}$ to $28^{\circ} 17^{\prime} 22^{\prime \prime} \mathrm{N}$ and $81^{\circ} 16^{\prime} 48^{\prime \prime}$ to $81^{\circ} 22^{\prime} 54^{\prime \prime} \mathrm{E}$ ) in Bardia District in western Nepal (Map 1 and 2). It covers an area of $16.95 \mathrm{sq}$. $\mathrm{km}$ which includes the core habitat of $5.27 \mathrm{sq}$. km. and peripheral area of villages and settlements spreading over $11.68 \mathrm{sq}$. km. The Blackbuck habitat is situated in Pataha Phanta.

The area is mostly marginal agricultural land and grazing land bordered on the three sides by the old riverbed and on the other side by scrub jungle (Lehmkuhl 1979). The study area has tropical monsoon climate and receives less rain than the east. 

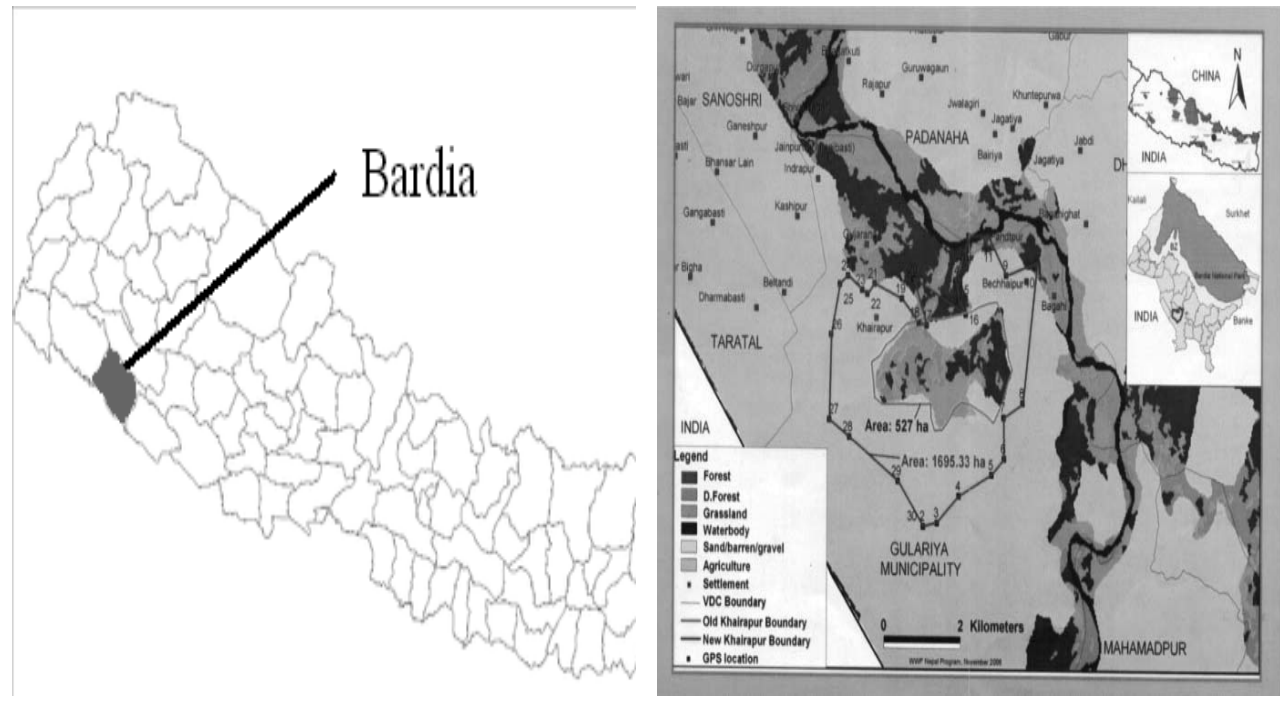

Map 1. Map of Nepal showing Bardia district. Map 2. Map of BCA, Khairapur, Bardia.

\section{MATERIALS AND METHODS}

The seasonal habitat use pattern of Blackbuck was studied by dividing the realized habitat of Blackbuck (area approximately $1.74 \mathrm{~km}^{2}$ ) into three blocks A, B and C of varying sizes (Table 1). The cart road to Panditpur passes across the Blackbuck habitat. The cart road divides the block $B$ on one side and the remaining two blocks on the other side.

The seasonal habitat use pattern was determined by direct count method and indirect count method. In direct count method, the number of individuals found in three blocks was recorded. The daily observation schedule was divided into three shifts: morning shift (07:00 am-10:00 am), noon shift (11:00 am-02:00 pm) and afternoon shift (03:00 pm-06:00 pm). The observations were done regularly in all seasons for a week.

In indirect count method, the number of fresh pellet of Blackbuck was counted by transect walk (later separated into block wise) within $4 \mathrm{~m}$ belt transect in all the seasons in a particular day.

Table 1. Description of the blocks in the Patahaphanta.

\begin{tabular}{|l|l|l|l|l|}
\hline & $\begin{array}{l}\text { Area (in } \\
\text { Bigaha) }\end{array}$ & $\begin{array}{l}\text { A r e a } \\
\left(\mathbf{k m}^{2}\right)\end{array}$ & Area (\%) & Remarks \\
\hline A & 64.29 & 0.527 & $30.30 \%$ & $\begin{array}{l}\text { Lies just in front of the guard post; direct moni- } \\
\text { toring of Blackbuck; open grassland with very } \\
\text { few scattered trees; was demarcated by the } \\
\text { way to Machan and covered the area on the } \\
\text { right of Machan }\end{array}$ \\
\hline
\end{tabular}




\begin{tabular}{|l|l|l|l|l|}
\hline B & 52.82 & 0.433 & $24.89 \%$ & $\begin{array}{l}\text { Lies in the east; is separated by the cart road; } \\
\text { has a patch of secondary forest and few scat- } \\
\text { tered trees }\end{array}$ \\
\hline C & 95.03 & 0.779 & $44.79 \%$ & $\begin{array}{l}\text { Lies on left of the way to Machan and covered } \\
\text { a large area including grassland and forest; } \\
\text { is also demarcated by the trench in east and } \\
\text { northeast }\end{array}$ \\
\hline Total & 212.148 & 1.739 & $100 \%$ & \\
\hline
\end{tabular}

The One -way ANOVA test was used to study the seasonal habitat use pattern of Blackbuck at Khairapur, Bardia. The version 2.15.1.0 R Foundation (2012) was used for the statistical analysis.

\section{Null and Alternative Hypothesis:}

\section{For direct count method}

Null hypothesis:

Ho: There is no significant difference in mean population distribution of Blackbuck in three different blocks due to four seasons.

Alternative hypothesis:

$\mathrm{H} 1$ : There is significant difference in mean population distribution of Blackbuck in three different blocks due to four seasons.

Null hypothesis:

Ho': There is no significant difference in mean population distribution of Blackbuck in four different seasons due to different blocks.

Alternative hypothesis:

$\mathrm{H} 1$ : : There is significant difference in mean population distribution of Blackbuck in four different seasons due to different blocks.

\section{For indirect count method}

Null hypothesis:

Ho: There is no significant difference in mean pellet distribution of Blackbuck in three different blocks due to four seasons.

Alternative hypothesis:

$\mathrm{H} 1$ : There is significant difference in mean pellet distribution of Blackbuck in three different blocks due to four seasons.

Null hypothesis: 
Ho: There is no significant difference in mean pellet distribution of Blackbuck in four different seasons due to different blocks.

Alternative Hypothesis:

$\mathrm{H} 1$ : : There is significant difference in mean pellet distribution of Blackbuck in four different seasons due to different blocks.

\section{RESULTS AND DISCUSSION}

The direct method showed that although block A covered only about $30.30 \%$ of the areas, $57.90 \%$ of Blackbucks were observed here. In contrast, in block $C$ which constitutes about $44.79 \%$ of the area, there were $23.43 \%$ of sightings. The block B which covers $24.89 \%$ of the area had $18.65 \%$ of Blackbuck recorded.

Table 2. Seasonal mean population of Blackbuck in different

blocks by direct count method.

\begin{tabular}{|l|l|l|l|l|}
\hline \multirow{2}{*}{ Season } & \multicolumn{3}{|c|}{ Blocks } & \multirow{2}{*}{ Total } \\
\cline { 2 - 4 } & A & B & C & \\
\hline Winter & 159 & 21 & 1 & 181 \\
\hline Spring & 114 & 28 & 31 & 173 \\
\hline Summer & 67 & 59 & 48 & 174 \\
\hline Autumn & 73 & 25 & 88 & 186 \\
\hline Total & 413 & 133 & 168 & 714 \\
\hline
\end{tabular}

The average herd size of Blackbuck was estimated to be 15.10 individuals. More number of herds was observed in block $A$ followed by block $B$ and block $C$. The number of herds observed in block A, B and C were 481 (48.48\%), 275 (27.72\%) and 236 (23.79\%) respectively indicating the safety to remain in small herds in those blocks accordingly.

Table 3. Number of herds observed and average herd size of Blackbuck.

\begin{tabular}{|l|l|l|l|l|l|}
\hline \multirow{2}{*}{ Season } & \multirow{2}{*}{$\begin{array}{l}\text { Total num- } \\
\text { ber of Black- } \\
\text { buck }\end{array}$} & \multicolumn{3}{|c|}{ Number of herds observed } & Average herd \\
\cline { 3 - 6 } & Block A & Block B & Block C & \\
\hline Winter & 3,799 & 168 & 84 & 42 & 12.92 \\
\hline Spring & 3,650 & 147 & 86 & 52 & 12.80 \\
\hline Summer & 3,643 & 84 & 63 & 70 & 16.78 \\
\hline Autumn & 3,890 & 82 & 42 & 72 & 19.84 \\
\hline Total & 14,982 & 992 & & & 15.10 \\
\hline
\end{tabular}


The indirect method showed that block A had a total of 373 pellets (36.46\%), block B had 292 pellets $(28.54 \%)$ and block $C$ had 358 pellets $(34.99 \%)$ and the results were similar to that of direct method which illustrate that Block $A$ was mostly used by Blackbuck followed by Block $\mathrm{C}$ and Block B.

The hypothesis on direct count method used to study the seasonal habitat use pattern of Blackbuck was tested by the statistical analysis (One-way ANOVA). It showed that the alternative hypothesis was accepted at $95 \%$ confidence level (Table 2-4). It may be due to controlled rotational grazing of livestock in winter and summer seasons; and no livestock grazing in spring and autumn seasons in the realized habitat of Blackbuck.

\section{For direct count method}

Table 3. Summary of mean population distribution of Blackbuck in three different blocks (One-way ANOVA).

\begin{tabular}{|l|l|l|l|l|l|l|}
\hline & DF & Sum sq & Mean sq & F value & Pr (>F) & Remarks \\
\cline { 1 - 4 } LC & 2 & 11638 & 5819 & 5.077 & 0.0334 & Significant \\
\cline { 1 - 3 } Residuals & 9 & 10315 & 1146 & & & \\
\hline
\end{tabular}

Table 4. Summary of mean population distribution of Blackbuck in four different seasons (One-way ANOVA).

\begin{tabular}{|l|l|l|l|c|c|c|}
\hline & DF & \multicolumn{1}{|c|}{ Sum sq } & Mean sq & F value & $\operatorname{Pr}(>\mathrm{F})$ & Remarks \\
\hline LC & 3 & 38 & 12.6 & 0.005 & 1 & Not significant \\
\cline { 1 - 6 } Residuals & 8 & 21915 & 2739.4 & & & \\
\hline
\end{tabular}

Also the statistical analysis (One-way ANOVA) used for the test of hypothesis on indirect count method to study the seasonal habitat use pattern of Blackbuck showed that showed the acceptance of alternative hypothesis at $99 \%$ level of confidence (Table 5-6). It may be due to poor visibility of pellets due to tall grasses except in winter season.

For indirect count method

Table 5. Summary of mean pellet distribution of Blackbuck in three different blocks (One-way ANOVA).

\begin{tabular}{|l|l|l|l|l|l|l|}
\hline & DF & Sum sq & Mean sq & F value & Pr (>F) & Remarks \\
\hline LC & 2 & 929 & 464 & 0.134 & 0.876 & Not significant \\
\cline { 1 - 4 } & 9 & 31182 & 3465 & & & \\
\hline
\end{tabular}


Table 6. Summary of mean pellet distribution of Blackbuck in four different seasons (One-way ANOVA).

\begin{tabular}{|l|l|l|l|l|l|l|}
\hline & DF & Sum sq & Mean sq & F value & $\operatorname{Pr}(>\mathrm{F})$ & Remarks \\
\hline LC & 3 & 24016 & 8005 & 7.912 & 0.00888 & $\begin{array}{l}\text { Highly signifi- } \\
\text { cant }\end{array}$ \\
\cline { 1 - 3 } Residuals & 8 & 8095 & 1012 & & & \\
\hline
\end{tabular}

It was noted that each block had its own importance. Block $A$ is an open grassland that is safe for Blackbuck due to prompt monitoring. It has the provision of good water source for Blackbuck. Block $B$ has Cassia tora which is good hiding place for the fawns. It was comparatively safe for Blackbuck when most of the areas of Block $A$ and $C$ were subducted in summer. Block $C$ has forest that provide shade to Blackbuck in sunny days and bushy vegetation like Glycosmis pentaphylla and Phyllanthus sp. were good hiding places for the fawns. Also the provisional crops like Rahar, wheat and maize planted in a small area of Block $A$ and $B$ attract Blackbuck in the absence of good forage in the area.

\section{ACKNOWLEDGEMENTS}

We extend our sincere thanks to Professor Dr. Ranjana Gupta, Head of Central Department of Zoology, Tribhuvan University, Kirtipur, Kathmandu for her kind cooperation. We are equally thankful to all the academic staffs of Central Department of Zoology, Tribhuvan University for their support and encouragements. We would like to thank the Department of National Parks and Wildlife Conservation (DNPWC) and Blackbuck Conservation Area (BCA) for granting permission to carry out this work. We are grateful to our family and friends for their continuous encouragements and supports.

\section{REFERENCES}

Chapagain, D. and J. Dhakal, 2002. CITES implementation in Nepal. DNPWC, Babarmahal and WWF Nepal Program, 82 (in Nepali).

Dinerstein, E.,1975. A status report on the Blackbuck of Banke district. Report DNPWC. Kathmandu.

Lehmkul, J. F., 1979. Some aspects of the life history of Blackbuck in Nepal. Journal of Bombay Natural History Society, 77:444-449.

R Development Core Team, 2012. R: A language and environment for statistical computing version 2.15.1.0 R Foundation for Statistical Computing, Vienna, Austria. Available at: http:// www.R-project.org.

Wegge, P. and P. Wilson,1976. The Blackbuck in Banke district. Report to HMGN. Kathmandu.

\section{AUTHOR'S ADDRESS}

\section{Suprabha Ban and Nanda Bahadur Singh}

Central Department of Zoology, Tribhuvan University, Kirtipur, Kathmandu, Nepal (email: mail2suprava@yahoo.com) 